\title{
Practice corner: using clinical prediction rules
}

\section{Scenario}

On inpatient teaching rounds, we recently discussed the admission of a 45 year old woman with chest pain. This patient presented to the emergency department after an episode of chest pain lasting approximately 30 minutes. The pain was pleuritic in nature, located on the right side of her chest, and was associated with shortness of breath. The patient reported no palpitations, diaphoresis, nausea, or vomiting. She had no relevant medical history, was taking oral contraceptives, and had no family history of cardiac or thromboembolic disease. Her vital signs, including oxygen saturation, were normal, as were the physical examination results. The working diagnosis was pulmonary embolus (PE), and she was started on intravenous heparin and scheduled for a ventilation-perfusion (V/Q) scan to be done within the next half hour.

After interviewing the patient with a team (2 residents, 3 interns, and 2 medical students) and reviewing the data, I asked the team to individually record their best estimate of the probability that this patient had PE. At first, the team was reluctant, in particular the third year residents, but with encouragement all members of the team scribbled down their best estimate. The probabilities were reviewed and were found to range from $5 \%$ to $80 \%$.

The importance of accurately determining the pre-test probability of disease is highlighted in figure 1. For our patient, resident 1 estimated the patient's pre-test probability of $\mathrm{PE}$ as being high (ie, 80\%). This pre-test probability combined with a low probability $\mathrm{V} / \mathrm{Q}$ scan result (likelihood ratio $=0.4$ ) gives a $61.5 \%$ probability of PE. ${ }^{1}$ This post-test probability is not sufficient either to rule in or rule out the diagnosis of PE and would prompt the resident to order further diagnostic tests, such as spiral computed tomography or pulmonary angiography, to better clarify the diagnosis. Resident 2 estimated the patient's pre-test probability as being low (ie, $5 \%$ ). When combined with the same $\mathrm{V} / \mathrm{Q}$ scan results, a final probability of $\mathrm{PE}$ of $2.1 \%$ is estimated. Resident 2 would probably stop any further diagnostic work up. Therefore, for the same patient, differing assessments of the pre-test probability of a PE by the 2 residents results in very different management strategies.

As a group, we decided it would be useful to see whether we could quickly find valid information about the patient's pre-test probability to help us with the diagnostic decision making process.

\section{Search and appraisal}

Information about the accuracy of diagnostic tests is difficult to find easily and quickly. Even more challenging is trying to find information about pre-test probability. Several potential sources could be used to determine pre-test probability, including our own clinical expertise, an audit of our practice, and the primary literature.

Clinical prediction rules (CPRs)* have been created to help clinicians arrive at more accurate estimates of pre-test probability. A CPR is a tool that quantifies the individual contributions that various components of the history, physical examination, and basic laboratory test results make towards the diagnosis, prognosis, or probable response to a treatment of an individual patient. ${ }^{2}$ CPRs are most useful when directed at frequent problems for which the stakes are high or cost saving is possible.

CPRs are most useful at the patient's bedside. However, they often require solving complex algorithms or performing tedious calculations to obtain a result. Therefore, many computer-based models have been developed on the internet and for personal digital assistants (PDAs). Electronic CPRs enable easy calculation of pre-test probability and give quick and perhaps more accurate estimates.

A small library of CPRs can be found at the Mount Sinai EBM web site (http://med.mssm.edu/ebm). These CPRs were chosen by a team of academic general internists for common medical problems and are organised by level of evidence, ${ }^{2}$ a measure of quality that describes whether the CPR is merely derived (level 4) or validated (levels 2 to 3 ) or whether an impact analysis of the CPR has been done (level 1). Such key information as the study population and the point of decision making at which the CPR should be applied are a link away. ${ }^{34}$ CPRs can also be downloaded for PDA devices from this web site.

\section{Applying the evidence}

In the scenario described above, the team referred to a CPR on the Mount Sinai EBM web site that was based on information from a study by Wells $e t a{ }^{\tilde{}}$ and from the PIOPED study. ${ }^{6}$ We first noted that the Wells CPR is considered level 3 evidence and that the study population included patients similar to ours. On the first page of the web site we found a list of respiratory symptoms and noted that our patient had 2 of these (dyspnea and pleuritic chest pain) (fig 2). 3 subsequent screens asked the team to record whether the patient had additional signs or symptoms

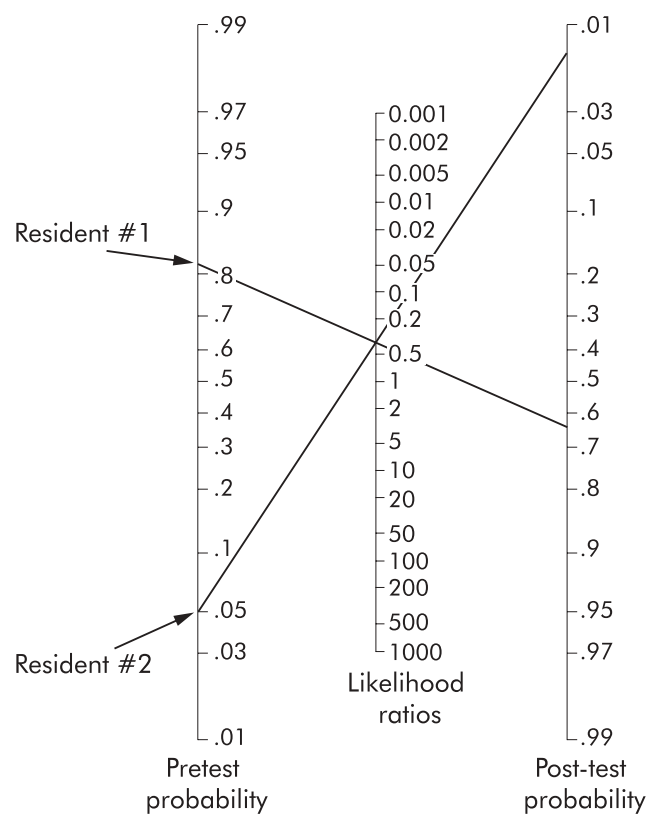

Figure 1. Resident 1 estimates the pre-test probability of PE at 80\%. This estimate results in a post-test probability of $61.5 \%$, given a low probability $V / Q$ scan (likelihood ratio=0.4). Resident 2 estimates the pre-test probability of $P E$ at $5 \%$ for the same patient. This results in a post-test probability of $2.1 \%$, given a low probability $V / Q$ scan. 


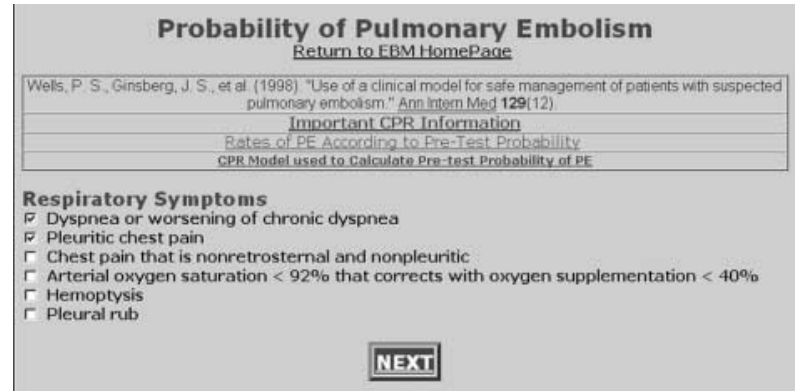

Figure 2. Respiratory symptoms.

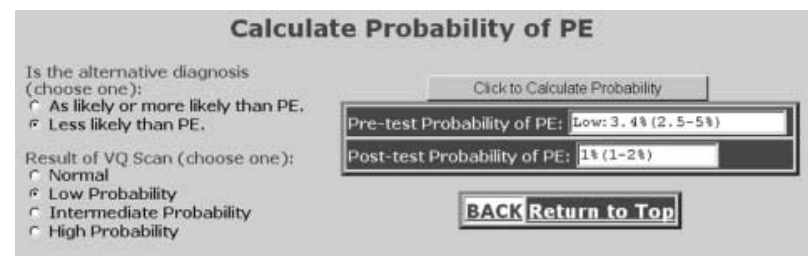

Figure 3. Alternative diagnosis, V/Q scan result, pre-test probability, and post-test probability.

and any of 8 listed risk factors for PE. We were also asked to consider whether an alternative diagnosis could be less likely than PE in this patient. Clicking the "calculate" button on this last screen (fig 3) produced an estimate of the patient's pre-test probability (3.4\%, 95\% CI 2.5 to 5.0$)$ and a post-test probability of PE of $1.4 \%$ (CI 1.0 to 2.0 ) following her low probability $\mathrm{V} / \mathrm{Q}$ scan. With this low post-test probability, the team felt comfortable ruling out PE.

Using the CPR and our patient's unique clinical circumstances, the calculation process took less than 1 minute. Our team, however, also spent several minutes reviewing the links for the level of evidence, population, and clinical decision model on the web site.

\section{Evaluating the process}

Medicine is still an art, and all clinicians have their own threshold of uncertainty that they are willing to accept before making a diagnostic or therapeutic intervention. CPRs are only tools in
Clinical prediction rule websites

\begin{tabular}{lll} 
Name & Website & Platform \\
InfoRetriever & www.InfoPOEMs.com & Internet \\
\hline MedRules & $\begin{array}{l}\text { pbrain.hypermart.net/ } \\
\text { medrules.html }\end{array}$ & PDA \\
\hline The Medical Algorithms Project & www.medal.org & MSExcel 97 \\
\hline Mount Sinai EBM web site & med.mssm.edu/ebm & Internet \\
\hline & $\begin{array}{l}\text { www.ohri.ca/programs/ } \\
\text { clinical_epidemiology/ }\end{array}$ & \\
Clinical Decision Rules & OHDEC/clinical.asp & Internet \\
\hline
\end{tabular}

this process and may serve to provide an objective standard by which clinicians can better quantify the pre-test probability of disease.

Several internet sites have both browser-based and PDAbased CPR calculators (table). These sites help us to practise evidence-based medicine in real time. In this scenario we were able to find and use a CPR in less than 2 minutes. However, few of these sites identify the level of evidence of a particular CPR or the population from which the rule was derived. Both types of information are necessary to apply the rule safely and in the correct setting.

*In ACP Journal Club, Evidence-Based Medicine, Evidence-Based Nursing, and Evidence-Based Mental Health, clinical prediction rules are referred to as clinical prediction guides.

$$
\begin{array}{r}
\text { THOMAS MCGINN, MD, MPH } \\
\text { CARLTON MOORE, MD } \\
\text { WARREN HO, MD } \\
\text { Mount Sinai Medical Center }
\end{array}
$$
New York, New York, USA

1 Sackett DS, Straus SE, Richardson WS, et al. Evidence-based medicine: how to practise and teach EBM. 2nd edition. Edinburgh: Churchill Livingstone, 2000

2 McGinn TG, Guyatt GH, Wyer PC, et al. Users' guides to the medical literature. XXII: how to use articles about clinical decision rules. EvidenceBased Medicine Working Group. JAMA 2000;284:79-84.

3 Wasson JH, Sox HC, Neff RK, et al. Clinical prediction rules. Applications and methodological standards. N Engl J Med 1985;313:793-9.

4 Laupacis A, Sekar N, Steill IG. Clinical prediction rules. A review and suggested modifications of methodological standards. JAMA 1997;277:488-
g4.

5 Wells PS, Ginsberg JS, Anderson DR, et al. Use of a clinical model for safe management of patients with suspected pulmonary embolism. Ann Intern Med 1998;129:997-1005.

6 Worsley DF, Alavi A. Comprehensive analysis of the results of the PIOPED study. prospective investigation of pulmonary embolism diagnosis study. $J$ 


\section{Journals reviewed for this issue*}

Acta Obstet Gynecol Scand
Age Ageing
Am J Cardiol
Am J Med
Am J Obstet Gynecol
Am J Psychiatry
Am J Public Health
Am J Respir Crit Care Med
Ann Emerg Med
Ann Intern Med
Ann Surg
Arch Dis Child
Arch Gen Psychiatry
Arch Intern Med
Arch Neurol

Arch Pediatr Adolesc Med
Arch Surg
Arthritis Rheum
BJOG
BMJ
BrJ Gen Pract
BrJ Psychiatry
BrJ Surg
CMAJ
Chest
Circulation
Cochrane Library
Crit Care Med
Diabetes Care
Gastroenterology

Gut

Heart

Hypertension

JAMA

J Am Coll Cardiol

J Am Coll Surg

J Am Geriatr Soc

J Clin Epidemiol

J Fam Pract

J Gen Intern Med

Infect Dis

Intern Med

J Neurol Neurosurg Psychiatry

J Pediatr
J Vasc Surg

Lancet

Med Care

Med J Aust

$\mathrm{N}$ Engl J Med

Neurology

Obstet Gynecol

Pain

Pediatrics

Rheumatology

Spine

Stroke

Surgery

Thorax

*Approximately 60 additional journals are reviewed. This list is available on request.

How to cite material from Evidence-Based Medicine

Citation of material from the Notebook

Milne R, Hicks N. Evidence-based purchasing [EBM Note]. Evidence-Based Medicine 1996 May-Jun;1:101-2.

Citation for material taken from a structured abstract, written without attribution by a staff member

Antihypertensive drugs decrease mortality, coronary events, and stroke in elderly persons [abstract]. Evidence-Based Medicine 1996 May-Jun;4:105. Abstract of: Pearce KA, Furberg CD, Rushing J. Does antihypertensive treatment of the elderly prevent cardiovascular events or prolong life? A meta-analysis of hypertension treatment trials. Arch Fam Med 1995;4:943-50.

Citation for material taken from a commentary to an article

Olds D. Commentary on "Home visiting programmes reduce childhood injury." Evidence-Based Medicine 1996 May-Jun;4:112. Comment on: Roberts I, Kramer MS, Suissa S. Does home visiting prevent childhood injury? A systematic review of randomised controlled trials. BMJ 1996;312:29-33.

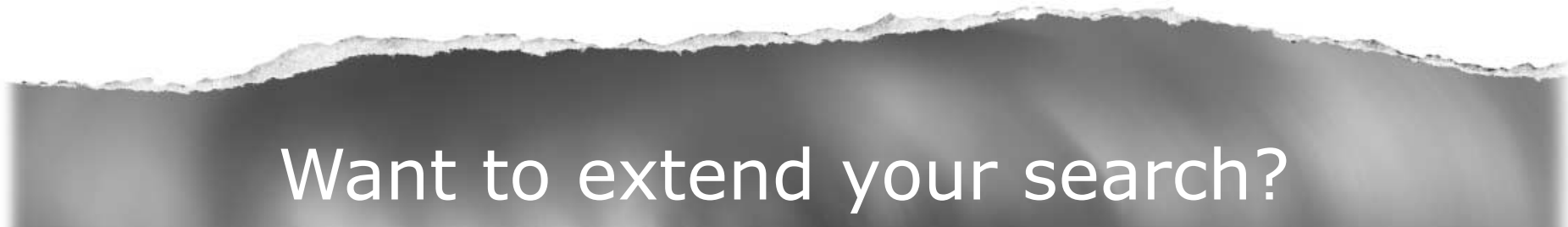

Cross journal searching

If you can't find what you are looking for in Evidence-Based Medicine you can extend your search across many of the more than 300 journals available for selection. You can restrict your search to specific subject areas (eg, clinical psychiatry, basic research), or select specific journals, or search all available titles.

www.evidence-basedmedicine.com 